\title{
Temporary Worker Fell from a Fixed Ladder inside a Building Being Renovated - Massachusetts
}

Release Date: June 26, 2015

Investigation: \# 13-MA-026-01
Massachusetts Department of Public Health Occupational Health Surveillance Program

\section{SUMMARY}

On August 30, 2013, a 58-year-old male laborer (victim) employed by a staffing agency and placed with a commercial builder/property manager (host employer) fell from a fixed ladder. The victim was standing on the fixed ladder while helping the superintendent of the host employer place filters on a roof when he fell approximately 17 feet to the concrete floor below. The host employer's superintendent did not see the victim fall, but heard a crash and turned around to find the victim on the floor behind him. He then placed a call for emergency medical services (EMS). EMS, the fire department and the local police arrived at the incident location within minutes. The victim was transported to a local hospital where he died of his injuries two days later.

Contributing factors identified in this investigation included roof access was only by a fixed ladder with no mechanism to get materials up to the roof, lack of training on ladders, and lack of a comprehensive contract between the staffing agency and the host employer.

The Massachusetts FACE Program concluded that to prevent similar occurrences in the future, employers should:

- Ensure that lifting mechanisms are available to get materials to a higher level when access is only by ladder; and

- Ensure that employees are trained in the proper use of ladders, including maintaining three point contact with the ladder.

To help prevent injuries and fatalities to temporary workers, staffing agencies and host employers must work together to inform workers about job hazards and provide training. Staffing agencies and host employers should:

- Develop a comprehensive contract that clearly states the tasks that will be performed and outlines the training and safety responsibilities for which each the staffing agency and the host employer are responsible.

In addition, commercial builders and architects should:

- Adopt and implement the concept of Prevention through Design (PtD) to ensure the safety and health of the end users of their buildings, such as designing roof access with stairways instead of fix ladders. 


\section{INTRODUCTION}

On November 7, 2013, the Massachusetts FACE Program was notified by the Occupational Safety and Health Administration that on the August 30, 2013, a male laborer was fatally injured after falling from a fixed ladder. On December 17, 2013, the Massachusetts FACE Program Director along with representatives from the Massachusetts Department of Labor Standards traveled to the staffing agency's office location and met with the office manager to discuss the incident. The police report, death certificate, information on both the staffing agency and the host employer, and the OSHA fatality and catastrophe report were reviewed during the course of the investigation.

\section{STAFFING AGENCY}

The staffing agency had been in business for approximately 26 years at the time of the incident. The staffing agency had over 600 locations throughout all 50 states and Canada. The agency provided temporary labor to a wide range of industries, including, construction, hospitality, manufacturing, and retail. The staffing agency was registered with the state as required by law in Massachusetts (G.L. c. 140, Sec. 46A - 46R) and had workers' compensation insurance also required by law in Massachusetts (G.L. c. 152, Sec. 25A). Employees did not have union representation.

\section{HOST EMPLOYER}

The host employer, a commercial builder and property manager, had been in business for 37 years and had approximately 100 employees. The host employer specialized in building retail stores, restaurants and banks. The host employer had offices in two states, neither of which were Massachusetts, but performed work in all 50 states. At the time of the incident, the host employer had one full-time employee, a superintendent, in Massachusetts for this job. Employees did not have union representation.

\section{CONTRACT}

A contract between the staffing agency and host employer existed. The contract stated that the victim was being placed as a laborer to do light cleaning, such as sweeping, dusting, and light debris removal within a single floor location. The contract also stated that the host employer would have direct supervision of the victim and that the victim must be included in the host employer's safety program, including any site-specific training and personal protective equipment. In addition, the staffing agency conducted and documented multiple site evaluations at the restaurant location where the victim was placed.

\section{SAFETY PROGRAMS AND TRAINING}

The staffing agency had an Injury and Illness Prevention Program (I2P2) and provided its employees general safety training. After the training, a 30 question, open book, safety and health exam was administered to employees to ensure that each employee comprehended the training. It was reported that the victim was provided the safety training and took the exam. The staffing agency also provided basic personal protective equipment (PPE) to employees to be placed with host employers. The PPE supplied is based on the occupation and industry in which the employee is placed, and, in this case, the victim was supplied with at least gloves.

The host employer also had an I2P2 and provided training and PPE to its full-time employees. The victim was not a full-time employee and was provided neither training nor PPE. While the victim was 
placed with the host employer, the host employer had provided two toolbox trainings, but neither of these trainings had been on ladder safety. In addition, the sign-in sheets for these toolbox trainings did not include the victim's name, which would indicate that the victim was not present for the toolbox trainings.

\section{VICTIM}

The victim was a 58-year-old laborer who was employed by a staffing agency and was placed with a commercial general contractor. The victim had been placed with the host employer for the two months leading up to the incident. The two months of work all took place at the incident location.

\section{INCIDENT LOCATION}

The incident location was a suburban open-air shopping area with retail and restaurant space. The shopping area was comprised of five buildings, totaling 193,000 square feet of space and 32 retail units. The location of the incident was inside an existing retail unit that was previously being used to house a store (Figure 1). The unit was going through a complete renovation to accommodate a restaurant that was moving into the space. The restaurant had opened for service the day before the incident occurred.

The incident occurred inside a small room at the back of the restaurant. This room had a concrete floor and an 18 1/2 foot vertical fixed ladder that was permanently attached to a wall. The fixed ladder had a 90 degree pitch and was used to access the building's roof through a roof hatch (Figure 2 and 3 ).

\section{INVESTIGATION}

It appears that these light cleaning tasks as described in the contract, were the only tasks the victim was performing until the day of the incident. On the morning of the incident, the victim and the host employer's superintendent were at the restaurant location. One of the first tasks the victim and the superintendent were to perform that day was to service the restaurant's ventilation scrubber units, which were located on the building's roof. The ventilation scrubber units are designed for commercial kitchens and filter out grease vapor, smoke, particulates and odors that are generated during cooking. The ventilation scrubber's filter dimensions were 20 inches wide by 24 inches long by 1.5 inches high.

To get the ventilation scrubber filters to the roof, the host employer's superintendent told the victim to climb the fixed ladder and that he would then pass him the filters to place on the roof. Once all of the filters were on the roof, the plan was that they would both climb onto the roof and install the filters into the ventilation scrubbers.

At the time of the incident, the victim was standing on the fixed ladder, near the top, approximately 17 feet high. The host employer's superintendent climbed up a couple of rungs on the fixed ladder and handed the victim some filters. The victim placed these filters onto the roof through the roof hatch. The superintendent then, standing on the concrete floor with his back to the fixed ladder and the victim, leaned over to pick up some more filters when he heard a loud crash. The superintendent turned around to see the victim lying on the ground behind. The victim landed within three feet of the base of the fixed ladder between the ladder and the superintendent. 
The superintendent immediately placed a call for emergency medical services (EMS). EMS, the fire department and the local police arrived at the incident location within minutes. The victim was transported to a local hospital where he died of his injuries two days later.

\section{CONTRIBUTING FACTORS}

Occupational injuries and fatalities are often the result of one or more contributing factors or key events in a larger sequence of events that ultimately result in the injury or fatality. The Massachusetts FACE team identified the following contributing factors in this incident.

- Access to the roof was only by a fixed ladder

- No mechanism to get materials up to the roof

- Lack of training on ladders by the host employer

- Lack of a comprehensive contract between the staffing agency and the host employer

\section{CAUSE OF DEATH}

The medical examiner listed the cause of death as blunt force injury of head, chest.

\section{RECOMMENDATIONS/DISCUSSION}

\section{Recommendation \#1: Employers should ensure that lifting mechanisms are available to get materials to a higher level when access is only by ladder.}

Discussion: In this case, the only access to the building's roof was through a roof hatch via a fixed ladder. If a hoist or another mechanism was available to get the filters to the roof, this would have eliminated using the ladder to accomplish this task and might have prevented the incident. A hoist would have limited the amount of time the victim spent on the ladder, especially standing at the top of the ladder twisting his body placing the filters on the roof and grabbing the next load of filters, which contributed to his fall.

A lifting mechanism could be something as simple as a manual pulley (with a breaking system), or it could be something more complex like a motorized hoist. When a lifting mechanism is selected to be incorporated into a building, it must be made sure the system is installed properly and that all workers are trained on how to use the system. Both the installation and training tasks should be based on information from the manufacturer. Employers should also develop standard operating procedures (SOPs) for using the lifting mechanism.

To ensure that hoisting and lowering tasks are performed safely with the lifting mechanism, it is important that the SOPs include, but not be limited to: ${ }^{1}$

- Developing clear verbal and hand signals so all employees can effectively communicate the hoisting instructions.

- Inspecting the pulley's components prior to each use.

- Securing the fall zone of the pulley to prevent others from being struck by the load.

- Ensuring the weight of the load does not exceed the capacity of the pulley system.

- Attaching and un-attaching the load safely.

- Ensuring that workers assigned to the fall zone never stand below a raised load and that these workers have plenty of space to stand clear of loads. 
- Ensuring proper personal protective equipment is worn when using rope pulley systems, such as gloves, and hardhats.

\section{Recommendation \#2: Employers should ensure that employees are trained in the proper use of ladders, including maintaining three point contact with the ladder.}

Discussion: In this case, the victim was not provided training by the host employer on ladders and then he was asked to use a fixed ladder to complete a task. OSHA requires that employers provide training to employees about proper ladder use and safety. The OSHA regulation 1926.1060, Training requirements states that training on ladders shall enable each employee to recognize hazards related to ladders and shall train each employee in the procedures to be followed to minimize these hazards. ${ }^{2}$ To help prevent injuries and fatalities while using ladders, training should include, but not be limited to: ${ }^{3}$

- Always using at least one hand to grasp the ladder (maintain three point contact with the ladder).

- Always face the ladder when climbing and descending the ladder.

- Never carry any object or load that may cause them to lose their balance and fall, use a tool belt or hoist to lift objects.

- Keeping centered between ladder side rails at all times ("belt buckle rule").

- Never overreach, lean, stretch, or make sudden moves while on the ladder.

All trainings and retraining, when necessary, should be performed by a competent person. OSHA defines a competent person as a person who, through training or knowledge, is capable of identifying existing and predictable hazards in the surroundings or working conditions that are unsanitary, hazardous, or dangerous to employees, and who has authorization to take prompt corrective measures to eliminate them. In addition, all training should be documented and the documentation should include who provided the training and their qualifications, the content of the training, workers who were trained, and the assessments of workers' comprehension of the training.

\section{Recommendation \#3: Staffing agencies and host employers should develop a comprehensive contract that clearly states the tasks that will be performed and outlines the training and safety responsibilities for which each the staffing agency and the host employer are responsible.}

Discussion: To help prevent injuries and fatalities to temporary workers, staffing agencies and host employers must work together. This includes ensuring temporary workers are not assigned tasks that are beyond the scope of work in the contract and informing temporary workers about job hazards and provide them with training. This can be accomplished by developing a comprehensive contract that clearly outlines the tasks to be performed and the safety responsibilities for which each the staffing agency and the host employer are responsible. ${ }^{4,5}$

In this case, there was a contract between the staffing agency and the host employer, which included that the temporary worker be provided with site specific training. The contract could have been more comprehensive and included specifics, such as prohibiting the use of ladders. In addition, staffing agencies have due diligence to ensure that the items outlined in the contract are being adhered too. In this case, although training was referenced in the contract, the victim was not being provided the trainings the host employer was providing to full-time employees. 
Contracts between staffing agencies and host employers should:

- Outline the specific tasks the temporary worker will be performing and state that the host employer will contact the staffing agency prior to altering the temporary workers scope of work;

- Describe who will provide both the general and the site-specific training for workers;

- List anticipated tasks and necessary personal protective equipment (PPE) for temporary workers, including who will provide it; and

- Designate agency and host point persons and provide the temporary workers with their names and phone numbers to contact with concerns that arise.

Once the contract is completed and signed, it should be reviewed with the temporary worker and they should receive a copy of the contract.

Host employers typically have the primary obligation to provide workplaces free of recognized hazards. The following is a general breakdown of responsibilities for both staffing agencies and host employers.

Staffing agencies should:

- Inquire about safety conditions at sites where they will be placing temporary workers;

- Provide general safety information to temporary workers in the language that they best understand;

- Make arrangements with host employers to ensure they provide temporary workers with site and job-specific safety training;

- Provide workers' compensation insurance and contact information to employees; and

- Record injuries/illnesses for temporary workers directly supervised on a day-to-day basis by the staffing agency.

Host employers should:

- Perform a work site hazard assessment to determine if hazards are present, or likely to be present, and then take steps to eliminate or control these identified hazards.

- Provide site and job-specific safety training to temporary workers in the language that they best understand. Training should include, but should not be limited to:

○ Ladder safety and fall protection;

- Safe operating procedures of equipment including location of emergency stops, and when and how to implement lockout/tagout procedures;

- Safe handling of chemicals to be used; and

- Site-specific emergency procedures.

- Provide workers with PPE for site-specific hazards, and train workers on how to properly fit and use PPE; and

- Record injuries/illnesses for temporary workers directly supervised on a day-to-day basis by the site employers.

It is important that both the staffing agency and the host employer recognize and understand their shared responsibilities and work together to assure workers are safe. 


\section{Recommendation \#4: Commercial builders and architects should adopt and implement the concept of Prevention through Design (PtD) to ensure the safety and health of all individuals who will interact with their buildings, such as designing roof access with stairways instead of fix ladders.}

Discussion: The concept of Prevention through Design (PtD), as it would relate to commercial builders and architects, is addressing safety and health needs during the design process to prevent or minimize hazards that could result in injuries, illnesses and fatalities to workers and tenants of the building. ${ }^{6}$ Applying PtD during the design phase of a new building or a building being renovated would initiate the process of thinking about how the building functions and all of the individuals that would come in contact or interact with the building to identify potential hazards. Once potential hazards are identified, the design can be altered to eliminate these hazards protecting the construction workers during the building phase, the tenants that will inhabit the building, and the workers performing building maintenance tasks.

In this case, the building where the incident occurred was an existing building that was completely renovated to accommodate the needs of the restaurant that was taking over the space. This renovation included adding multiple ventilation scrubber units for the restaurant on the roof. With the addition of these units on the building's roof it increased the number of times workers would have to access the roof via the fixed ladder through the roof hatch to service these units.

During the design phase for the renovation of this building, if $\mathrm{PtD}$ was applied it could have been determined that alternate access to the roof was needed, especially because the plan was to add multiple scrubbing ventilation units to the rooftop. The alternate access to the roof could have been in the form of a stairway leading to the roof. The addition of a stairway to the roof would eliminate all of the fall-related and other hazards that ladders introduce to a work setting.

\section{REFERENCES}

1. Code of Federal Regulations, 29 CFR 1926.554 Overhead hoists. Washington DC: U.S. Printing Office, Office of the Federal Register.

2. OSHA. Code of Federal Regulations. 29 CFR 1926.1060. Training requirements. Washington, DC: U.S. Printing Office, Office of the Federal Register.

3. OSHA. Code of Federal Regulations. 29 CFR 1926.1053. Ladders. Washington, DC: U.S. Printing Office, office of the Federal Register.

4. Massachusetts FACE project, FACE Facts, Temporary Agencies and Worksite Employers Share Responsibility for Keeping Temporary Workers Safe, April 2012.

www.mass.gov/eohhs/docs/dph/occupational-health/temp-workers.pdf. Date accessed: March 9, 2015.

5. OSHA/NIOSH. Recommended Practices: Protecting Temporary Workers, 2014.

www.osha.gov/Publications/OSHA3735.pdf. Date accessed: March 9, 2015.

6. NIOSH Program Portfolio: Prevention Through Design. www.cdc.gov/niosh/topics/ptd. Date accessed: March 31, 2015. 
Figure 1 - Building where the incident occurred

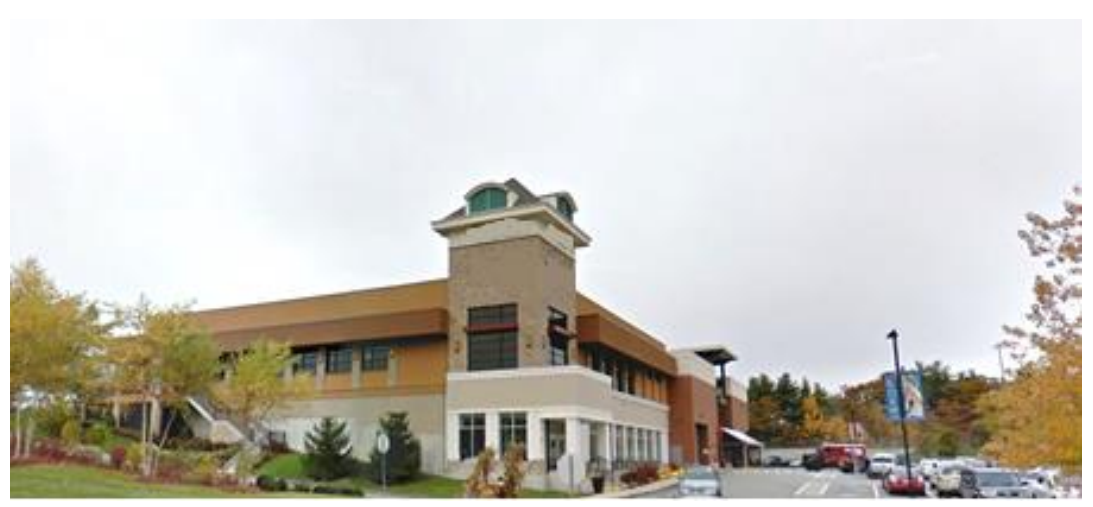

Figure 2 - Example of a fixed ladder

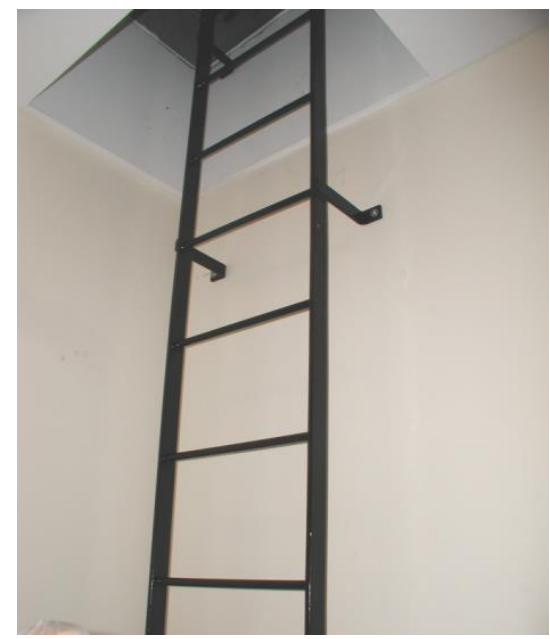

Figure 3 - Example of a roof hatch with a fixed ladder

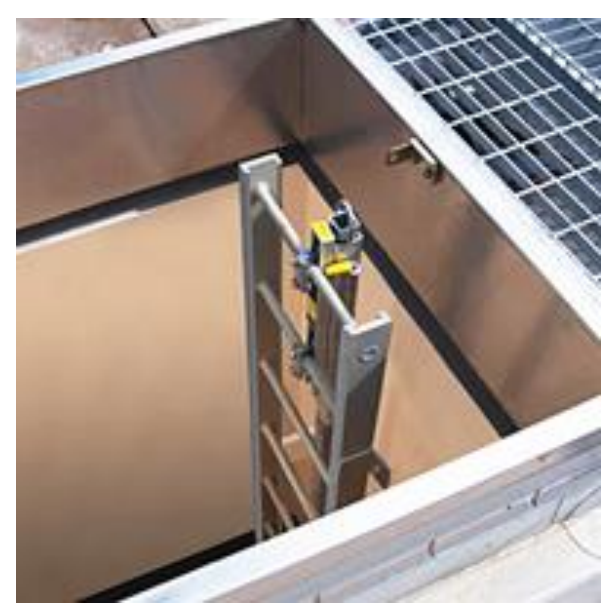

